\title{
A constituição do Centro de Preservação da História Ferroviária do Rio Grande do Sul de Oitenta
}

The make-up of railroad history preservation center from Rio Grande do Sul in the eighties

\author{
Cinara Isolde Koch Lewinski* \\ cinarakoch@gmail.com
}

Resumo: Este artigo tem por objetivo debater um tema ligado ao patrimônio histórico e surgiu da necessidade de se desenvolver um estudo sobre a atuação do Programa de Preservação do Patrimônio Histórico no Rio Grande do Sul, a partir das carências constatadas através da investigação sobre o assunto. Por isso, o Museu do Trem, antiga Estação Ferroviária de São Leopoldo, se tornou o objeto de pesquisa, pois, abrigou o Centro de Preservação da História Ferroviária do nosso Estado. A metodologia sobre o estudo está concentrada na pesquisa documental, com a finalidade de investigar a reconstituição histórica do Preserve/fe em nosso Estado, na década de 1980. A pesquisa que está sendo elaborada é embasada teoricamente na história cultural e consiste em demonstrar a importância de se fazer um estudo mais aprofundado sobre a iniciativa do Governo Federal em preservar o patrimônio ferroviário do Rio Grande do Sul. Portanto, este artigo tem a pretensão de discorrer sobre composição do patrimônio ferroviário gaúcho por meio de uma breve análise sobre os motivos que levaram à construção de seu acervo utilizando-se de critérios para seleção dos objetos que perderam as suas atribuições funcionais e passaram a ser ressignificados como patrimônio.

Palavras-chave: patrimônio, ferrovia, Preserve

Abstract: This paper aims to discuss a theme connected to the historical heritage and emerge from the the necessity of developing a study about the situation from Heritage Preservation Program in Rio Grande do Sul, from the lacks identified through research on the subject. Therefore, the Museum of Train, former São Leopoldo Station, became the object this research, therefore, took the Preservation Centre Railroad history of our state. The methodology of the study is focused on documentary research, in order to investigate the historical reconstitution of the Preservelfe in our state, in the 1980s. This research that is being developed is grounded theory in cultural history and is to demonstrate the importance of making further study on the initiative of the Federal Government to preserve the railroad heritage from Rio Grande do Sul. So, this article tries to discuss the makeup of gaucho heritage railroad thought a brief analysis on the reasons that led to the construction of its collection using criteria for selection of the objects that have lost their functional duties and became reinterpreted as heritage.

Keywords: heritage, railroad, Preserve

*Mestranda em História pela Universidade Federal do Rio Grande do Sul (UFRGS), bolsista/taxa CAPES/PROSUP. 


\section{Introdução}

$\mathrm{O}$ interesse em analisar as ações do Preserve/ $\mathrm{fe}^{1}$ sobre o patrimônio cultural no Rio Grande do Sul surgiu no decorrer do meu trabalho como historiógrafa no Museu do Trem de São Leopoldo -RS. Atuando na área da pesquisa da instituição percebi que havia a necessidade de conhecer a forma como se constituiu o acervo. No decorrer do estudo, constatei que seria importante estudar o período que o Preserve/fe atuou e organizou o Centro de Preservação da História da Ferrovia no Rio Grande do Sul no Museu do Trem-SL, pois foi neste momento que se ampliou o número de peças e de documentos da instituição. Então, comecei a buscar fontes bibliográficas, fotografias e documentos sobre o período para compreender as motivações políticas que criaram o Preserve/fe e as suas ações que levaram a desempenhar um papel importante na organização da reserva técnica do Museu do Trem-SL. Nesse sentido, se buscou o entendimento das influências que acarretaram na preservação do patrimônio ferroviário que passou a ganhar maior destaque na esfera pública e tornou os espaços de memória mais acessíveis ao público. Contudo, darei ênfase à preocupação Governamental com a preservação do patrimônio ferroviário que surgiu com a necessidade de se estabelecer os critérios para a definição de bens móveis e imóveis de valor artístico, histórico e cultural referentes à ferrovia que deveriam ser patrimonializados pelo antigo Ministério dos Transportes. Enfim, ao estudar as motivações que legitimaram um projeto, como é o caso do Preserve/fe, é possível ponderar sobre "os objetos culturais produzidos, os sujeitos produtores e receptores de cultura, como também os processos que envolvem a produção e difusão cultural, os sistemas que dão suporte a estes processos e sujeitos, e por fim as normas a que se conformam as sociedades através da consolidação de seus costumes" (BARROS, 2003, p.17).

\section{Os bens ferroviários como patrimônio ${ }^{2}$}

\begin{abstract}
Ao longo dos anos vem se modificando o conceito de monumento histórico, que deixa de ser encarado como coisa monumental, extraordinariamente rica e imponente, e passa ser encarado também sob os prismas social e econômico, porquanto se trata de um marco de cultura, em que tais fatores responderam por sua edificação e permanência. Passa-se então a entender um monumento como algo que represente caracteristicamente a cultura do povo de uma região, num determinado período da história. Neste sentido, monumento pode ser tanto uma deslumbrante catedral, quanto uma simples e rústica casa de taipa. O valor real é a importância histórica e cultural e não a riqueza que ostenta em seus adornos. ${ }^{3}$ (PRESERVE, 1991, p.12)
\end{abstract}

Este trecho retirado do manual de edificações, produzido pelo antigo Ministério dos Transportes, em 1991, sugere como o patrimônio ${ }^{4}$ da ferrovia era compreendido pelo Preserve/fe .No fragmento, cabe ressaltar o significado das palavras "cultura" e "monumento histórico"5. O primeiro termo foi utilizado para assinalar as várias concepções que o antigo Ministério dos Transportes imprime a palavra cultura. Ponderando sobre a conjuntura na qual se constituíram os bens ferroviários, a terminação tem a definição de

\footnotetext{
${ }^{1}$ Como consta no manual de edificações do governo federal, o Preserve atuou como Programa ministerial até 1986. A partir daí, o Preserfe agiu na preservação do patrimônio ferroviário. Como este setor seguiu as diretrizes do programa anterior, seguirei utilizando Preserve/fe, pois não falarei de ações específicas executadas ano a ano no Rio Grande do Sul.

${ }^{2}$ O Decreto da Constituição Brasileira de 1937 instituiu como patrimônio “o conjunto de bens móveis e imóveis existentes no País e cuja conservação seja de interesse público, quer por sua vinculação a fatos memoráveis da história do Brasil, quer por seu excepcional valor arqueológico ou etnográfico, bibliográfico ou artístico".

${ }^{3}$ Este trecho foi escrito com referência a bibliografia "L'ESPACE du Voyage:les gares. Monuments historiques, Paris nº6".

${ }^{4}$ Este vocábulo era repetidamente empregado durante a Revolução Francesa e foi rapidamente abandonado em seguida, devido a sua ambiguidade. Reapareceu no Brasil para indicar os monumentos históricos e parcialmente substitui-los ao longo dos anos 1960 (CHOAY, 2011, p.27).

${ }^{5}$ Neste artigo, não pretendo definir e aprofundar os conceitos de cultura e de patrimônio, pois seria necessário um trabalho bem mais extenso para desenvolvê-los.
} 
"kultur, [...] desenvolvida desde o século XIX pela etimologia e a antropologia cultural, que a tornou sinônimo de 'civilização' ou, em outras palavras, de uma obra coletiva e criadora" (CHOAY, 2011, p. 27). Em outro momento, através do Preserve/fe utiliza a designação para reconhecer o valor político da cultura como questão de Estado.

Já a segunda expressão, “monumento histórico", foi utilizada para nomear o patrimônio ferroviário edificado. Seguindo as medidas da Carta de Veneza (1964) e da Declaração de Amsterdã (1975), o governo federal brasileiro passou a ajustar as suas decisões com uma definição de patrimônio ampliada pautando-se nos "referenciais culturais dos povos, pela percepção dos bens culturais nas dimensões testemunhais do cotidiano" (FUNARI; PELEGRINI, 2006, p.32). Dessa forma, "essa abertura temática permitiu que construções menos prestigiadas ou mais populares, como moinhos, mercados públicos ou estações de trem, fossem reconhecidos como patrimônio" (FUNARI;

PELEGRINI, 2006, p.32). Sendo assim, para entender o processo de patrimonialização ${ }^{6}$ dos bens ferroviários, é preciso explicar a ideia de democratização do patrimônio que se potencializou nas últimas décadas do séc. XX no Brasil, em um momento de transformações na sociedade promovidas pela mundialização ${ }^{7}$. As mudan- ças ocorridas também produziram modificações na noção de patrimônio, ou seja, as compreensões tradicionais de conhecimento histórico determinadas numa perspectiva positivista de história, em torno das grandes narrativas que destacavam fatos liderados pelas elites da nação e de seus heróis, foram sendo trocadas por pesquisas históricas ressaltando as construções e apropriações cotidianas de fenômenos sociais. Com a ampliação temática se alargaram os bens compreendidos como patrimônio, os quais passaram a vincularem-se a sujeitos comuns e demais objetos do cotidiano.

Então, com a incorporação de novas concepções nas práticas de tombamento através da democratização da cultura, o patrimônio da ferrovia no Brasil passou a pertencer ao inventário dos bens a serem preservados. Assim sendo, a ferrovia que por mais de um século era símbolo de modernidade e progresso estava sendo ressignificada como patrimônio cultural ${ }^{8}$, onde grupos sociais passaram a buscar uma representação de sua memória coletiva. ${ }^{9}$

No entanto, começou-se a pensar efetivamente numa política patrimonial sobre os bens ferroviários no Brasil a partir do momento em que a RFFSA ${ }^{10}$ foi incluída no Programa Nacional de Desestatização. Logo, todo o patrimônio ferroviário não operacional construído a partir dos meados do séc. XIX no Brasil

\footnotetext{
${ }^{6}$ Segundo Maria Cecília de Alvarenga Carvalho, as sociedades históricas sempre se encontraram com os remanescentes materiais das civilizações passadas. O encaminhamento dado a esses remanescentes é uma intervenção realizada em relação a sua continuidade e transmissão às sociedades futuras ou ao desaparecimento do existente não mais considerado funcional ao tempo presente. A patrimonialização parece ser um recurso atual ao abordarmos com os remanescentes dos sistemas de produção passada, principalmente aqueles mais contemporâneos provenientes do capitalismo industrial.

${ }^{7}$ Conforme, Choay, o símbolo espacial da "mundialização" é esquematizado "pelo conjunto de redes de infraestruturas técnicas, materiais e imateriais, normalizadas e fora de escala, pelo canal por onde se transmitem desde então os fluxos de informação e circulação de bens e de pessoas, e que conferem uma nova identidade-global-ao nosso planeta". (CHOAY, 2011, p.31) A partir daí, um procedimento de normalização planetária dos lugares de vida e das atividades, rompe as ligações e em um mesmo movimento, exclui os estabelecimentos e as paisagens humanas de sua função simbólica, garantidora da diferença e da identidade, transformando-se em sinônimo de perda e cujo horizonte é uma sociedade globalizada (CHOAY, 2011, p.30).

${ }^{8}$ Aloísio Magalhães, ao assumir a direção do IPHAN em 1979, propõe uma associação do conceito antropológico de cultura às ações de uma política pública para o patrimônio. Pois, acreditava que a identidade cultural brasileira estava em processo e o passado era importante quando tornava possível aquele procedimento.

9 “A memória coletiva é frequentemente o produto de um empilhamento de estratos memoriais muito diversos, podendo essas camadas sedimentares ser alteradas aquando das perturbações de memória. Dessa forma, se podemos admitir que Les lieux de mémoire, [...], nos falam realmente de algumas modalidades de memória coletiva (memória real, memória-Estado, memória-nação, memória-cidadão, memória-patrimônio), os lugares são na maior parte das vezes a condensação de memórias plurais mais ou menos antigas, frequentemente conflituosas e interagindo umas com as outras "(CANDAU,2011, p. 91-92)

${ }^{10}$ A Rede Ferroviária Federal Sociedade Anônima pelo decreto no 473 de 10 de março de 1992 foi incluída no PND.
} 
passou a ser responsabilidade do IPHAN $^{11}$, ganhando destaque no Patrimônio Cultural Brasileiro devido à importância socioeconômico na sociedade. ${ }^{12}$

Essas ações constituem-se o marco inicial da organização da patrimonialização dos seus bens que continuaram a ser tratados dessa forma, mesmo após a liquidação e extinção da RFFSA, através das ações promovidas pela sociedade civil organizada e por instituições públicas, municipais e estaduais e pelo IPH$A N,[\ldots]$ (CARMO, 2014, p. 65).

Porém, vários museus ferroviários foram criados no Brasil durante a execução dos projetos do Preserve/fe, entre a década de 1980 e início dos anos 1990, ou seja, antes do IPHAN assumir a responsabilidade pela salvaguarda do acervo ferroviário. Sendo assim, os museus instituídos pelo programa federal que salvaguardaram o patrimônio ferroviário estabeleceram valores e sentidos, expressando uma profunda alteração dos sistemas produtivos esgotados pelo capitalismo industrial, ou seja, representaram a própria sociedade em constante modificação. Nesse sentido, o trecho extraído do catálogo do Preserve/fe, escrito por Carlos Aloysio Weber ${ }^{13}$, no período da inauguração do Centro de Preservação da História da Ferrovia no Rio Grande do Sul, expressa os valores que o governo federal pretendia imprimir através do patrimônio cultural ferroviário ${ }^{14}$ gaúcho:

E nosso objetivo é preservar o que está e vem sendo tecnologicamente substituido, seguindo a filosofia do Ministério dos
Transportes ao criar o PRESERVE, nesta homenagem àqueles que, com seu pioneirismo, ajudaram, desde o século passado, o progresso do nosso País (MINISTÉRIO DOS TRANSPORTES, 1985, p. 11).

Portanto, percebe-se claramente que a prática da preservação do patrimônio histórico passa a ser assunto do governo federal com a preocupação em manter e conservar as edificações que são eleitas pelo seu legado histórico e cultural que evocavam "uma memória que não é mais a do Estado-Nação" (REIS, 2012, p. 59) ${ }^{15}$. Então, a mundialização desencadeou uma ansiedade que levou a uma "obsessão com a memória e a preservação, entre a amnésia e a vontade de nada esquecer" (REIS, 2012, p. 60) e sendo assim, propiciou diversas adaptações possíveis das representações, se ajustando conforme os interesses sociais, com as determinações e oposições políticas que se conferem no mundo humano. (BARROS, 2003, p.21).

\section{PRESERVE: Programa de Preservação do Patrimônio Histórico}

O Programa de Preservação do Patrimônio Histórico do Ministério dos Transportes criou através da Portaria $n^{0} 292$, de 24 de abril de 1980, da Secretaria Geral, um projeto com o objetivo de preservar a história dos transportes. Inicialmente, a proposta era conhecer o material histórico do Ministério supracitado, reunir em local adequado, preservar e restaurar, com o intuito de

\footnotetext{
${ }^{11}$ Art. 9o Caberá ao Instituto do Patrimônio Histórico e Artístico Nacional - IPHAN receber e administrar os bens móveis e imóveis de valor artístico, histórico e cultural, oriundos da extinta RFFSA, bem como zelar pela sua guarda e manutenção. (http://www.planalto.gov.br/ccivil_03/_ato20072010/2007/lei/111483.htm).

12 "Um dos maiores acervos ferroviários de valor histórico é sem dúvida o arquitetônico. As estações ferroviárias tornaram-se importantes referências para as comunidades. Em torno delas, muitas cidades se desenvolveram e outras surgiram com a implantação da ferrovia. [...] A história do Brasil no final do século passado e início deste século está diretamente ligada ao advento da ferrovia" (PRESERVE, 1991, p.06).

${ }^{13}$ Presidente da Rede Ferroviária Federal Sociedade Anônima (29/03/1282-30/03/1985).

${ }^{14} \mathrm{O}$ patrimônio ferroviário oriundo da RFFSA engloba bens imóveis e móveis, incluindo desde edificações como estações, armazéns, rotundas, terrenos e trechos de linha, até material rodante, como locomotivas, vagões, carros de passageiros, maquinário, além de bens móveis como mobiliários, relógios, sinos, telégrafos e acervos documentais. Segundo inventário da ferrovia são mais de 52 mil bens imóveis e 15 mil bens móveis, classificados como de valor histórico pelo Programa de Preservação do Patrimônio Histórico Ferroviário (Preserfe), desenvolvido pelo Ministério dos Transportes, instituição até então responsável pela gestão da RFFSA. A gestão desse acervo constitui uma nova atribuição do Iphan e, para responder à demanda, foi instituída a Lista do Patrimônio Cultural Ferroviário, por meio da Portaria Iphan nº 407/2010, com 639 bens inscritos até 15 de dezembro de 2015. (http://portal.iphan.gov.br/pagina/detalhes/127)

${ }^{15}$ Segundo José Carlos Reis, o patrimônio é atualmente, local - nacional-universal.
} 
documentar a evolução tecnológica de todos os modais. Mais tarde, o projeto transformou-se em programa e buscou preservar a memória do desenvolvimento dos meios de transporte no Brasil, por meio da salvaguarda de bens avaliados históricos e representativos de cada modal. Porém, o programa foi levado adiante somente com o modal ferroviário e a continuidade foi possível, pois, o material para a preservação ainda estava disponível e dos quais alguns ainda faziam parte de bens ativos operacionais da RFFSA.

Em 1986, o Preserve deixou de ser ministerial e passou a ser administrado pela RFFSA ${ }^{16}$, que adotando as bases das diretrizes instituídas pelo programa inicial, desenvolveu o Setor de Preservação do Patrimônio Histórico Ferroviário- Preserfe ${ }^{17}$, assumindo a responsabilidade pela manutenção e orientação dos trabalhos referentes à preservação na empresa.

Então, o Preserve/fe se engajou na busca de salvaguardar o patrimônio histórico da ferrovia e para isso, definiu os critérios de seleção que determinaram o que seria representativo para a construção da memória e se manteria preservado. Entretanto, era um programa do governo e por isso, representava o esforço de criar uma imagem de si mesmo, desconstruindo a ideia de centralismo político e propondo uma representação mais democrática. Partindo deste ponto de vista, deliberou sobre a conservação desses objetos e símbolos do passado a partir de interesses políticos em nome de interesses públicos. Ou seja, a prática discursiva do
Governo federal ficou materializada nos espaços organizados pelo Programa. O Preserve/fe fortemente influenciado por questões políticas e ideológicas não deu atenção patrimonial a todos os bens não operacionais da ferrovia. Segundo os dados quantitativos levantados pela Secretaria do Patrimônio da União, foram transferidos à União cerca de 52 mil unidades cadastrais correspondentes a terrenos e edificações não-operacionais da extinta RFFSA, distribuídos em 19 Estados e mais de 1000 Municípios em todo o país, sendo que no Rio Grande do Sul eram 1271 edifícios e 1696 terrenos cadastrados $^{18}$. Porém, antes desse levantamento, o governo federal já tinha uma ideia da dimensão do patrimônio e conforme, o trecho retirado do documento administrativo do Centro de Preservação da História Ferroviária do Rio Grande do Sul, se tornou a justificativa pela forma como se organizou o Programa:

\section{Devido ao numeroso acervo que deveria ser preservado em todas as superin- tendências regionais, optou-se pela criação dos Centros de Preservação a nivel de Estados e núcleos históricos a nivel de cidades (ARQUIVO DO MU- SEU DO TREM-SL). ${ }^{19}$}

Destes bens, conforme os dados levantados no catálogo em 1988 sob a coordenação de Maria Elisa Carrazzoni $^{20}$, foram construídos 16 centros e núcleos de preservação em oito anos de Preserve/fe. Deste modo, antigas construções ferroviárias foram restauradas e adaptadas para receber os vários centros de preservação da história da ferrovia no Brasil. Em nosso Estado, o

\footnotetext{
${ }^{16}$ Sendo uma das entidades participantes junto ao Departamento Nacional de Estradas de Rodagem, a Petrobrás e Empresas vinculadas. Foi uma das pioneiras no desenvolvimento do Projeto, considerando o seu grande número de material histórico e a sensibilidade do ferroviário para com a sua história. (Trecho retirado do documento administrativo do Centro de Preservação da História Ferroviária do Rio Grande do Sul- Arquivo do Museu do TremSL com a denominação: Rede Ferroviária Federal S.A conta a sua história através do Museu do Trem-SL)

${ }^{17}$ Setor de Preservação do Patrimônio Histórico Ferroviário ligado a Superintendência de Patrimônio e mais tarde transformado em Gerência.

${ }^{18}$ Dados levantados no documento de orientação aos municípios e entidades sem fins lucrativos. Disponível em http://www.rffsa.gov.br/principal/ Destinacao\%20do\%20Patrimonio\%20da\%20RFFSA.2010. Acesso no dia 21/04/2016.

${ }^{19}$ Trecho retirado do documento com a denominação "Rede Ferroviária Federal S.A conta a sua história através do Museu do Trem-SL".

${ }^{20}$ Em 1979, convocada pelo Ministério dos Transportes para organizar o trabalho de preservação do patrimônio histórico daquela pasta, sugeriu a criação do Programa de Preservação do Patrimônio Histórico do Ministério dos Transportes, PRESERVE (CARRAZZONI, 2001, p. 186).
} 
Museu do Trem $^{21}$ abrigou o sexto Centro de restaurados. O primeiro prédio abrigou a exposição de Preservação no Brasil ${ }^{22}$ que foi reinaugurado no dia 09 longa duração e o segundo foi transformado em reserva de março de 1985, como Centro de Preservação da His- técnica, onde se preservou uma parte do acervo docutória Ferroviária no Rio Grande do Sul. mental, audiovisual e tridimensional da Viação Férrea

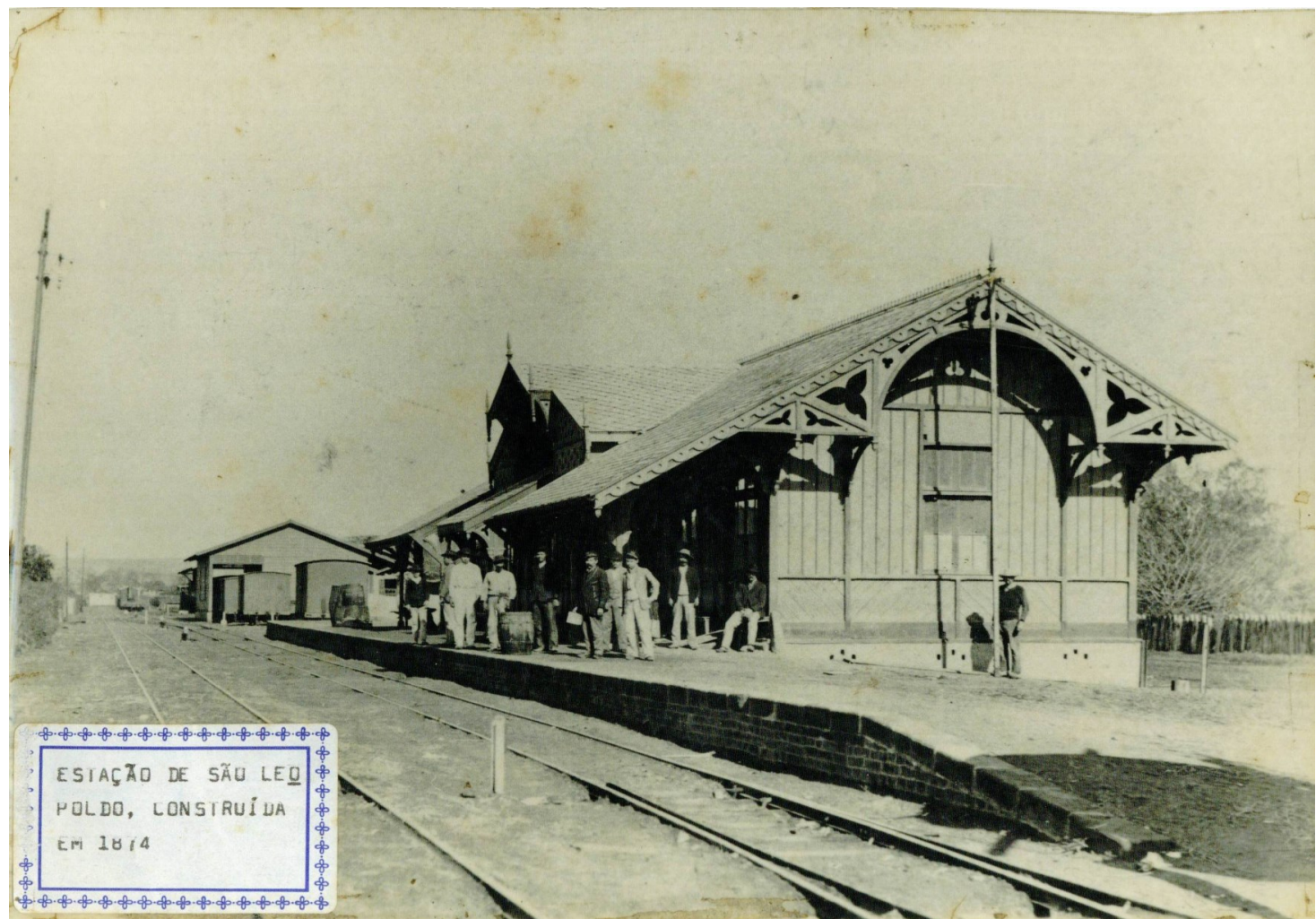

Foto 1-Imagem do Museu do Trem de São Leopoldo no séc. XIX (Arquivo do Museu do Trem-SL). Picture 1-Image São Leopoldo Train Museum in the century. XIX (Train-SL Museum Archive).

...As realizações, as experiências, as lutas e os legados dos que nos antecederam empregando outros métodos de trabalho e vivendo outro estágio tecnológico ainda não se apagaram e puderam ser resgatados a fim de que possamos transmitilos às gerações que nos sucederem. E para isso, cria-se o CENTRO DE PRESERVAÇÃO DA HISTÓRIA DA FERROVIA DO RIO GRANDE DO SUL, que em São Leopoldo e em sua Estação Ferroviária pioneira abrigará a memória deste meio de transporte em solo gaúcho. (PRESERVE 1991, p. 12).

Mas, antes disso, na década de 1980, a antiga estação ferroviária e o armazém de São Leopoldo foram do Rio Grande do Sul/Rede Ferroviária Federal Sociedade Anônima. Durante os anos subsequentes, a instituição produziu documentos administrativos que foram arquivados e permaneceram no Museu. A partir desse acervo começou a se problematizar através da História Cultural sobre a constituição do acervo ferroviário do Rio Grande do Sul e até ponderar sobre o papel do Estado historicamente marcado pela concentração de poderes que soube fazer uso desta instituição para legitimar sua representação, ideologia e simbolismo, como podemos verificar neste trecho da documentação da instituição:

\footnotetext{
${ }^{21}$ No dia 26 de novembro de 1976, foi inaugurado o Museu do Trem, sendo estabelecido num convênio entre a R.F.F.S.A. (Rede Ferroviária Federal Sociedade Anônima) e o Museu Histórico Visconde de São Leopoldo. O Museu ficou instalado na Estação ferroviária de São Leopoldo, que ainda estava em funcionamento. O prédio tornou-se unicamente sede do Museu em 1980, quando a estação ferroviária foi desativada. Dois anos mais tarde, a R.F.F.S.A. inicia um longo processo de restauro a fim de recuperar o Museu, já bastante alterado, visando devolvê-lo a seus moldes originais.

${ }^{22} 1^{\circ}$ Centro de Preservação da História Ferroviária São João Del Rey (1981), $2^{\circ}$ Centro de Preservação da História Ferroviária de Recife (1982), $3^{\circ}$ Centro de Preservação da História Ferroviária do Ceará (1982), $4^{\circ}$ Centro de Preservação da História Ferroviária de Curitiba (1982), $5^{\circ}$ Centro de Preservação da História Ferroviária do Rio de Janeiro (1984) e $6^{\circ}$ Centro de Preservação da História Ferroviária de São Leopoldo (1985). (PRESERVE 1991, p.19-24).
} 
E nosso objetivo é preservar o que está e vem sendo tecnologicamente substituido, seguindo a filosofia do Ministério dos Transportes ao criar o PRESERVE, nesta homenagem àqueles que, com seu pioneirismo, ajudaram, desde o século passado, o progresso do nosso País. (PRESERVE, 1985, p. 11)

Portanto, o discurso de Carlos Aloysio Weber, Presidente da RFFSA, além de expor as estratégias políticas que foram divulgadas com a patrimonialização dos bens ferroviários não operacionais também traz a ideia da promoção de políticas públicas que surgiram com a exigência da sociedade por uma maior democratização do patrimônio e do acesso à informação. E do mesmo modo, Maria Eliza Carrazzoni, secretária executiva do Preserve/fe, enfatiza sobre a abertura temática do que é definido como patrimônio:

Mas, nosso objetivo não é apenas a preservação do testemunho material: é acima de tudo a valorização do homem, daquele que, vencendo obstáculos de toda ordem e em todos os niveis, soube adaptar a tecnologia dos transportes, vinda de países em estágio de desenvolvimento mais adiantado, as nossas necessidades. Desde o Engenheiro ao mais simples trabalhador de linha, ao marin- heiro, ao operário das oficinas de manutenção, o nosso trabalho procura mostrar os traços da Inteligência, do preparo técnico e da dedicação que deixaram na sua vida profissional. (PRESERVE, 1985, p. 9)

No entanto, a arquitetura das edificações era o foco de maior preocupação no projeto elaborado para o Brasil, e mais especificamente para o Rio Grande do Sul. Por sua importância na construção de memórias individuais e coletivas ${ }^{23}$, as edificações ferroviárias foram consideradas de grande valor histórico pelos agentes do Programa. Ou seja, foram atribuídas as antigas estações um grande valor histórico, consideradas como referências pelas comunidades. Muitas cidades se desenvolveram e outras surgiram em torno das estações e trilhos da ferrovia, portanto, ganharam status como sendo o símbolo do desenvolvimento urbano.

De acordo com o gerente, o arquiteto Cláudio Bacalhau, na apresentação, em 1991, do Manual de preservação de edificações ferroviárias antigas, era importante - resguardar a memória da história da arquitetura no Brasil, pois a arquitetura ferroviária, para o PRESERFE, da influência do prédio na evolução urbana (PROCHNOW, 2014, p.26).

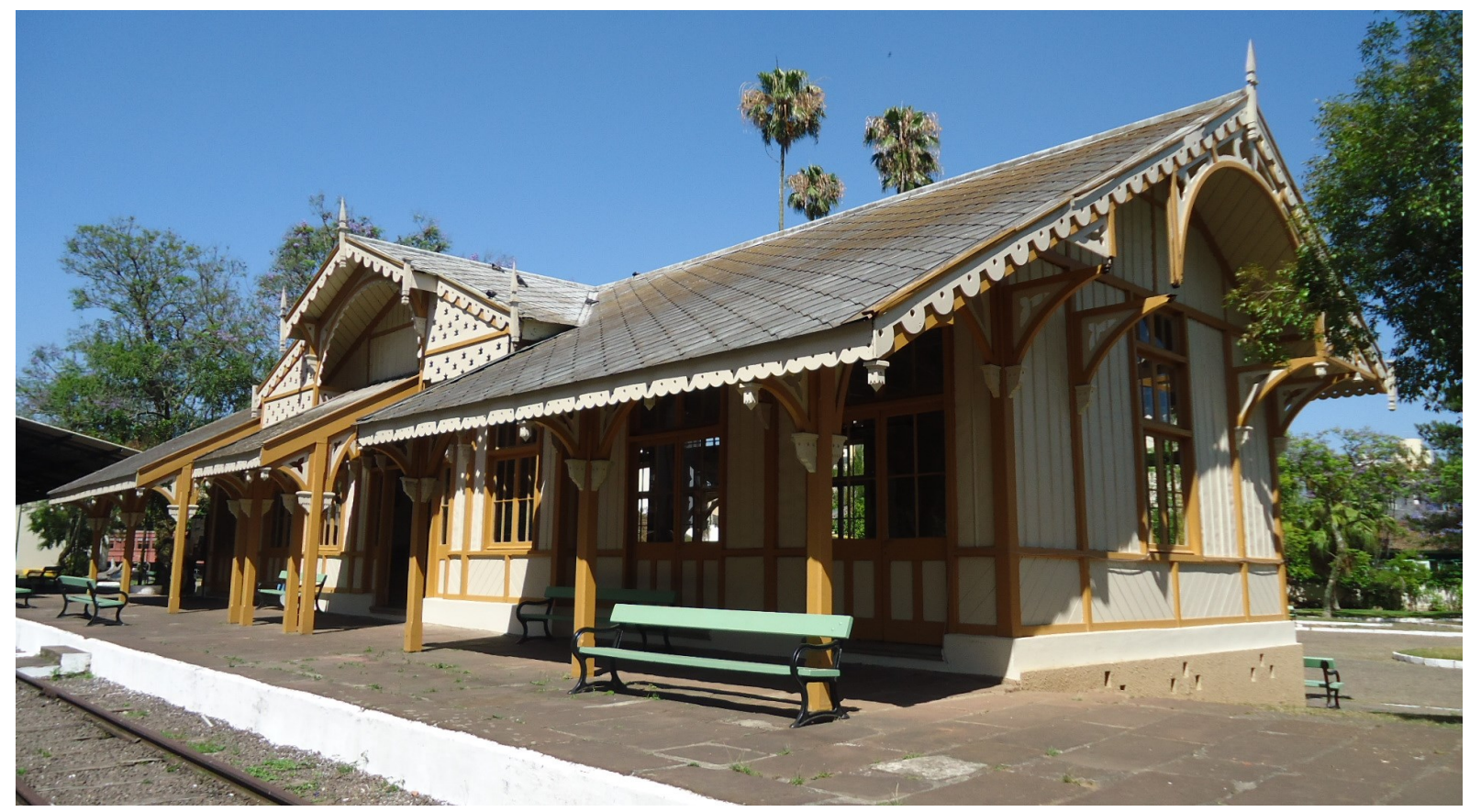

Foto 2-Atual imagem do Museu do Trem de São Leopoldo (Arquivo do Museu do Trem-SL)

Picture 2-Current image of São Leopoldo Train Museum (Train-SL Museum Archive)

\footnotetext{
${ }^{23}$ Por mais individuais que sejam as nossas memórias, "a memória individual tem sempre uma dimensão coletiva, sendo a significação dos acontecimentos memorizados pelo sujeito sempre medida pelo diapasão da sua própria cultura" (CANDAU, 2011, p. 97).
} 
Legitimando a necessidade da preservação das antigas estações, Carrazzoni faz alusão a estação ferroviária de São Leopoldo por sua importância histórica e arquitetônica e que devido a esses atributos foi poupada da destruição por decisão de agentes responsáveis pela empresa metroviária:

\section{A Estação Ferroviária de São Leopoldo entrou em operação a 14 de abril de 1874, quando do início do tráfego fer- roviário entre Porto Alegre e São Leo- poldo. Sua arquitetura, singular em relação aos demais prédios da região e mesmo do resto do Estado, testemunha a presença inglesa no Rio Grande do Sul. \\ Preservá-la era indispensável, especial- mente porque as obras do Trem Metro- politano da Trensurb viriam projetar suas linhas sobre a área ocupada pelo prédio da estação pioneira, urgindo a ação de protegê-la. Graças a com- preensão dos responsáveis pela Tren- surb, o progresso desta vez não destruiu o passado (MINISTÉRIO DOS TRANS- PORTES, 1985, p. 9).}

Apesar desse relato da coordenadora do Programa expressar a conquista pela conservação da edificação ferroviária no local de origem, também evidencia o poder de decisão das autoridades que muitas vezes escondem os verdadeiros motivos que levam "escolhas expressas em projetos políticos historicamente constituídos" (FUNARI; PELEGRINI, 2006, p. 57), nos quais determina os bens a serem preservados e aqueles condenados ao esquecimento.

Sendo a preservação de monumentos uma atividade necessariamente seletiva, uma constante opção entre o conservar e o destruir (ativo ou passivo, no sentido de não impedir a destruição), ela será exercida por determinados agentes, $e$ segundo determinados critérios, que orientam e também legitimam o processo de atribuição de valores - e consequentemente, a preservação (FONSECA, 1997, p. 52).

Portanto, as autoridades ainda detêm o poder de decisão sobre os bens que são dignos de preservação, através da legislação e por meio de estratégias interligadas por diversos grupos sociais, apesar da ampliação temática do patrimônio e a maior participação de grupos que outrora não estavam incluídos no processo.

\section{Considerações Finais}

Os comentários citados acima demonstram a importância de se fazer uma análise mais aprofundada sobre a construção dos centros de preservação do patrimônio ferroviário enquanto política de governo. Primeiramente, é preciso levar em consideração as motivações que induziram a implantação dos Centros de Preservação da História Ferroviária em todo o Brasil com a atuação do Preserve/fe e desse modo, ir além do que aparentemente se expõe. Neste artigo, o estudo de caso se restringiu ao Centro de Preservação da História Ferroviária do Rio Grande do Sul integrado num programa federal.

Conforme apresentado, os bens não operacionais da RFFSA foram selecionados para exposição ao público e para a composição da reserva técnica nos espaços organizados pelo Preserve/fe com o intuito de divulgar a história ferroviária, estabelecida com base nas técnicas e narrativas empregadas no campo da Museologia, coordenada por Maria Elisa Carrazzoni. Os centros cumpriam o objetivo de disseminar a história dos transportes, mas também assumiram a função de edificar uma cultura da preservação ferroviária, elegendo referenciais significativos de acordo, com a memória oficializada através de um complexo trabalho de eleição de objetos e monumentos que relembravam a ocupação do território, evolução das cidades, dos grupos étnicos, da história, da ciência e da tecnologia.

A escolha dos lugares para implantação dos centros e núcleos considerou a importância adquirida pela ferrovia para a comunidade local, a estrutura existente e $\mathrm{o}$ apelo social, mas principalmente o valor histórico e 
arquitetônico das edificações. Portanto, a estação de São Leopoldo-RS foi um desses espaços eleitos para abrigar a história ferroviária local, enfatizando a estrutura e operação da ferroviária, através do Centro de Preservação da História da Ferrovia do Rio Grande do Sul. Apesar, da relevância que o Programa federal teve para a preservação do acervo ferroviário gaúcho que pode ser salvaguardado, não se pode negar o caráter elitista da instituição analisada. O projeto elaborado para o Rio Grande do Sul privilegiou a preservação de acervos que remetiam a determinados aspectos da his- tória ferroviária e a influência dos europeus e norteamericanos em nosso país, desse modo à salvaguarda da antiga estação de São Leopoldo é um exemplo disso. Por fim, o acervo ferroviário gaúcho em exposição na década 1980, privilegiava a necessidade de se resguardar a memória da história da ferrovia no Brasil que refletia um momento de mudanças conjunturais promovidas pela globalização que exauriram o patrimônio industrial,porém, não foi utilizado para repensar sobre a diversidade cultural das regiões, desigualdade social e econômica em nosso país.

\section{Referências bibliográficas}

ABREU, Regina. Patrimônio Cultural: tensões e disputas no contexto de uma nova ordem discursiva. In: Apostila Seminários Temáticos Arte e Cultura Popular, Primeira Edição, 2006/2007. Museu Casa do Pontal, Rio de Janeiro, p. 54-63.

ALMANAQUE DA RFFSA. O Preserve/ Preserfe. 2010. Disponível em: http://almanaquedarffsa.blogspot.com.br. Acesso em 23/08 /2015.

AMADO, Janaína; FERREIRA, Marieta de Moraes (orgs.). Usos \& abusos da História Oral. 4. ed. Rio de Janeiro: Editora FGV, 2001.

BARROS, José D’Assunção. História Cultural: Um Panorama Teórico e Historiográfico. Textos de História, Brasília, v. 11, 2003, p. 145-171.

CANDAU, Joel. Memória e identidade. São Paulo: Contexto, 2011.

CARMO, Mônica Elisque do. Trilhos e Memória (Preservação do Patrimônio Ferroviário em Minas Gerais). Belo Horizonte, Dissertação (Mestrado em Ambiente Construído e Patrimônio Sustentável), Escola de Arquitetura da Universidade Federal de Minas Gerais, 2014.

CARRAZZONI, Maria Elisa. Anos 70: um Museu de Arte sob Regime Autoritário. Rio de Janeiro: Senai /RJ CFP Artes Gráficas.

. MT PRESERVE (Programa de Preservação do Patrimônio Histórico do Ministério dos Transportes, 19801988). Brasília: PRESERVE, CCP, 1988.

CARVALHO, Maria Cecília de Alvarenga. Memória social e patrimônio ferroviário em Além Paraíba. Belo Horizonte, Dissertação (Mestrado em Ciências Sociais), Pontifícia Universidade Católica de Minas Gerais, 2010.

CHOAY, Françoise. A alegoria do patrimônio. 3. ed. - São Paulo: Estação Liberdade: UNESP, 2006.

. O patrimônio em questão: analogia para um combate. Belo Horizonte, MG: Fino Traço, 2011.

Decreto-Lei $\mathrm{N}^{\mathrm{o}}$ 25. Organiza a proteção do patrimônio histórico e artístico nacional. http://www.planalto.gov.br/ ccivil_03/decreto-lei/Del0025.htm. 1937. Acesso em 17 abr. 2016.

FONSECA, Maria Cecília Londres. O patrimônio em processo: trajetória da política federal de preservação no Brasil. 2. ed.- Rio de Janeiro: UFRJ; Minc-.Iphan, 2005. 
FUNARI, Pedro Paulo Abreu; PELEGRINI, Sandra de Cássia Araújo. Patrimônio Histórico e Cultural. Rio de Janeiro: Jorge Zahar Ed. 2006.

Legislação sobre patrimônio cultural [recurso eletrônico]. - 2. ed. - Brasília: Câmara dos Deputados, Edições Câmara, 2013.

Lei no 9491 - Presidência da República. Altera procedimentos relativos ao Programa Nacional de Desestatização. Disponível em: <http://www.planalto.gov.br/ccivil_03/leis/L9491.htm.> 1997. Acesso em 23 ago. 2015.

Lei n ${ }^{0} 11.483$ - Presidência da República. Encerra o processo de liquidação e extinta a Rede Ferroviária Federal S.A. Disponível em: <http://www.planalto.gov.br/ccivil_03/_ato2007-2010/2007/lei/111483.htm.> 2007. Acesso em: 23 ago. 2015.

MINISTÉRIO DOS TRANSPORTES - Preserve; rede ferroviária federal s.a. - Superintendência Regional Porto Alegre. Centro de Preservação da História da Ferrovia no Rio Grande do Sul. 1. Ed. Porto Alegre: Ed. Gráfica Metrópole, 1985.

. Manual de preservação de edificações ferroviárias antigas. 1. ed. Rio de Janeiro: Rede Ferroviária Federal S.A, 1991,61p.

MONASTIRSKY, Leonel Brizolla. Ferrovia: Patrimônio Cultural - Estudo sobre a ferrovia brasileira a partir da região dos Campos Gerais (PR). Florianópolis, Tese (Doutorado em Geografia), Universidade Federal de Santa Catarina, 2006.

Portal IPHAN. Atribui ao IPHAN a responsabilidade sobre o Patrimônio Ferroviário. 2007. Disponível em: $<$ http://portal.iphan.gov.br/pagina/detalhes/127>. Acesso em: 20 abr. 2016.

PROCHNOW, Lucas Neves. O Iphan e o patrimônio ferroviário: a memória ferroviária como instrumento de preservação. Rio de Janeiro, Dissertação (Mestrado Profissional em Preservação do Patrimônio Cultural), Instituto do Patrimônio Histórico e Artístico Nacional, 2014.

REIS, José Carlos. O tempo histórico como "representação intelectual". Revista do Patrimônio (Histórico e Artístico Nacional). n. 34, 2012, p.45-66.

Submissão: $22 / 05 / 2016$

Aceite: $25 / 10 / 2016$ 